\title{
O acesso livre à produção acadêmica como subsídio para políticas públicas: um exercício sobre o Banco de Teses da Capes
}

Open access to academic scholarship as a public policy resource: a study of the Capes database on Brazilian theses and dissertations

Teresa da Silva Rosa

Professora do Programa de Pós-graduação em Ciências Sociais e pesquisadora do Núcleo de Estudos Urbanos e Socioambientais/ Centro Universitário Vila Velha; pesquisadora colaboradora do grupo de pesquisa Ciência, Natureza, Informação e Saberes e do Centro de Referência em Segurança Alimentar e Nutricional//Universidade Federal Rural do Rio de Janeiro (UFRRJ).

tsrosaprof@yahoo.com.br

Rua Comissário José Dantas de Mello, 21 29102-770 - Vila Velha - ES - Brasil

\section{Maria José Carneiro}

professora do Programa de Pós-graduação de Ciências Sociais em Desenvolvimento, Agricultura e Sociedade/UFFRJ.

mjtcarneiro@gmail.com

Av. Presidente Vargas, 417/9. andar

20071-003 - Rio de Janeiro - RJ - Brasil

Recebido para publicação em maio de 2009.

Aprovado para publicação em março de 2010.
DA-SILVA-ROSA, Teresa; CARNEIRO, Maria José. O acesso livre à produção acadêmica como subsídio para políticas públicas: um exercício sobre o Banco de Teses da Capes. História, Ciências, Saúde-Manguinhos, Rio de Janeiro, v.17, n.4, out.-dez. 2010, p.955-974.

Resumo

O acesso ao conhecimento científico é meio importante para informar e validar posições na formulação de políticas públicas. O recurso aos conhecimentos é, contudo, problemático diante da diversidade e extensão dessa produção. Entendendo que a comunicação entre os campos da ciência e da política depende da divulgação do conhecimento produzido e das possibilidades de acesso, realizamos uma pesquisa empregando uma ferramenta de busca digital de acesso livre, com o objetivo de mapear o conhecimento sobre a contribuição da agricultura na conservação da biodiversidade. No presente artigo, apresentamos uma leitura crítica do acesso às informações divulgadas pelo Banco de Teses do Portal de Periódicos da Capes.

Palavras-chave: conhecimento científico; políticas públicas; acesso livre; produção acadêmica; Brasil.

\section{Abstract}

Access to scientific knowledge is a valuable resource than can inform and validate positions taken in formulating public policy. But access to this knowledge can be challenging, given the diversity and breadth of available scholarship. Communication between the fields of science and of politics requires the dissemination of scholarship and access to it. We conducted a study using an open-access search tool in order to map existent knowledge on a specific topic: agricultural contributions to the preservation of biodiversity. The present article offers a critical view of access to the information available through the Capes database on Brazilian theses and dissertations.

Keywords: scientific knowledge; public policy; open access; scholarship; Brazil. 
$\mathrm{A}$ pesar do investimento feito nas últimas décadas em projetos de conservação de recursos naturais, as políticas públicas têm respondido de modo ainda pouco satisfatório às mudanças ambientais globais, principalmente aquelas que relacionam as questões da sustentabilidade ambiental ao desenvolvimento econômico. A literatura voltada para a discussão dessas questões aponta um fato conhecido: as atividades humanas são, intrinsecamente, impactantes e o são ainda mais dentro do atual modelo de produção, que é altamente consumidor de recursos naturais. Uma redefinição das atividades econômicas, tomando por base a perspectiva do pensamento ecológico, nos leva a uma concepção da economia mais respeitosa dos ciclos naturais que sustentam os ecossistemas (GeorgescuRoegen, 1995; Coméliau, 2006).

É no contexto da inter-relação entre os dois sistemas, o natural e o social, e da ponte entre ciência e formulação de políticas públicas ambientais que se insere a temática central deste estudo: a disponibilização de conhecimentos científicos produzidos nas instituições de ensino superior no Brasil, particularmente os que abordam a relação entre agricultura e biodiversidade e mais especificamente a contribuição da agricultura familiar na conservação da biodiversidade. Supostamente, os formuladores de políticas públicas deveriam integrar o conhecimento existente de maneira a ampliar o leque de opções nas tomadas de decisão sobre uma prática cuja meta seria diminuir o impacto da ação humana sobre os recursos naturais (Da-Silva-Rosa, 2005). No presente artigo tratamos dos limites e das possibilidades de acesso às teses produzidas sobre o tema em instituições acadêmicas brasileiras.

No seu papel de mais bem compreender o mundo e a sociedade, a ciência cria subsídios importantes que, transpostos para o campo da política e da ação, podem ser instrumentos úteis para que as políticas públicas cumpram seus objetivos. Sob outro ângulo, os responsáveis pela formulação de políticas públicas podem se abastecer da produção científica existente para consolidar, justificar ou legitimar as tomadas de decisão (Davies, Nutley, 2001; Nutley, Walter, Davies, 2007). Nesse sentido, uma etapa importante no processo de elaboração de medidas políticas seria o acesso - ou a difusão - ao conhecimento científico e o seu uso por parte dos tomadores de decisão. No entanto, considerando que o mundo da ciência e o mundo da política têm os seus próprios modus operandi, a comunicação entre eles, apesar de essencial, pode ser bastante difícil de ser construída. Esse diálogo pode criar ou apresentar ruídos indesejáveis, os quais podem se refletir na falta de resposta efetiva na fase de implantação das políticas públicas. Talvez isso esteja ocorrendo no âmbito das políticas ambientais.

Dois são os objetivos deste artigo. Num primeiro momento, apresentamos o mapeamento das teses baseado no Banco de Teses que integra o Portal de Periódicos da Coordenação de Aperfeiçoamento de Pessoal de Nível Superior (Capes), do Ministério da Educação. Esse levantamento buscou identificar as teses de doutorado defendidas nas universidades do país $^{1}$, a partir de palavras-chave previamente escolhidas e relacionadas a dois grandes temas: biodiversidade e agricultura. A seguir discutimos os obstáculos enfrentados e as possibilidades oferecidas pelo Banco de Teses da Capes, ferramenta de acesso livre.

Assim, o levantamento visa não apenas a identificar o conhecimento produzido em um dado campo temático, mas também, e principalmente, a possibilitar a discussão sobre a utilidade desse veículo como fonte de subsídios para os formuladores de políticas públicas. 
Ressalte-se que não se pretende discutir a qualidade do conhecimento produzido ou das provas sobre as quais ele se sustenta, mesmo porque as evidências e os conhecimentos sobre as quais as decisões políticas poderão se fundamentar são de natureza bastante diversificada e complexa, o que justificaria outro estudo.

\section{O acesso a conhecimentos: a busca do diálogo entre os campos da ciência e da política}

O contexto geral que motivou inicialmente este estudo é marcado pela investigação sobre o recurso da metodologia de formulação de políticas públicas baseada em evidências (evidence-based policies/EBP), em políticas ambientais de interface com a agricultura familiar. Este é o foco de interesse do projeto internacional de pesquisa Agricultura e Desenvolvimento Sustentável nas Problemáticas das 'Políticas Baseadas em Evidência-Biosoc', desenvolvido pelo grupo de pesquisa Cinais, do Programa de Pós-graduação de Ciências Sociais em Desenvolvimento, Agricultura e Sociedade, da Universidade Federal Rural do Rio de Janeiro (UFRRJ), em cooperação com o Institut National de Recherche Agronomique, da França e a Western Cape University, da África do Sul. ${ }^{2}$ Uma das etapas do projeto consistiu no levantamento da produção científica sobre o tema, publicada em periódicos nacionais de três áreas do conhecimento: economia, ciências sociais e ciências biológicas. No caso brasileiro especificamente, foram incluídas as teses catalogadas no Banco de Teses da Capes. Cabe registrar que o Brasil é o único país, entre os três participantes do projeto, que possui tal ferramenta.

Historicamente, a abordagem da EBP é usual nas áreas da saúde, educação, justiça e assistência social, sendo mais rara em campos interdisciplinares como o ambiental. Na expectativa de ampliar o escopo de informações acessíveis aos formuladores de políticas e, com isso, otimizar os resultados pretendidos pelas políticas públicas ${ }^{3}$, a EBP sustenta que as decisões devem se pautar em evidências, ou seja, resultados de pesquisas validadas empiricamente (Davies, Nutley, 2001). Isso levaria a supor a existência de uma ponte entre pesquisa científica e prática política. No entanto, como verificamos na primeira etapa do projeto de pesquisa, o procedimento de recorrer ao conhecimento científico é raramente incorporado às práticas que antecedem a formulação de políticas públicas no Brasil, ao menos no caso das ambientais (Carneiro, Rosa, Medeiros, 2008).

Um dos aspectos polêmicos do debate sobre a EBP é a própria noção de evidência. No campo da saúde, em que tal abordagem já é institucionalizada, evidência é definida como algo que "fornece provas para a tomada de decisão, abrange resultados de pesquisas, bem como consenso de especialistas reconhecidos ..." (Galvão, Sawada, Rossi, 2002, p.692). A ideia de prova é, portanto, fundamental. Contudo, podemos acrescentar que ela supõe uma certeza num campo onde as incertezas vêm ocupando cada vez mais espaço. Ressaltase também o caráter eclético dessa definição, quando a evidência pode ser tanto resultado de pesquisas como o consenso de experts.

Acrescenta-se que as evidências são originadas em um contexto específico, não sendo, muitas vezes, replicáveis em outras situações - e isso é muito mais pertinente às ciências humanas e sociais (Hastrup, 2004). Ademais, as evidências podem apontar uma ação ou 
solução que nem sempre são acatadas pelos tomadores de decisão na política pública. Isso porque o campo das negociações políticas ou das disputas de interesses usuais, no processo de elaboração de uma política (Juntti, Russel, Turnpennyc, 2009), pode exigir outros procedimentos, que muito se distanciam da racionalidade científica.

Além disso, não podemos dizer que as decisões políticas baseadas em evidências científicas são, necessariamente, as mais acertadas. Traduzindo evidência por conhecimento científico, compreendemos que o recurso a tais fontes é um em vários critérios, entre aqueles que os tomadores de decisão podem lançar mão a fim de fundamentarem suas decisões (Davies, Nutley, 2001). Como verificamos, a formulação de políticas públicas pode se sustentar também nas informações decorrentes da experiência pessoal ou profissional dos técnicos envolvidos (Carneiro, Laurent, Medeiros, 2008; Carneiro, Rosa, Medeiros, 2008).

Discorrendo sobre o que importa para a tomada de decisão, Juntii, Russel e Turnpennyc (2009, p.208) propõem uma definição de evidência considerada por eles mais concisa, a qual é entendida como: "todos os tipos de ciência e o conhecimento das ciências sociais gerados pelo processo de investigação e análise, dentro ou fora da instituição de tomada de decisão". ${ }^{4}$ Assim, o mais relevante no processo de formulação de políticas seriam os conhecimentos no sentido mais amplo - com o que concordamos.

A hegemonia do conhecimento produzido segundo a racionalidade científica na tomada de decisão é outro aspecto bastante presente nesse debate (Juntii, Russel, Turnpennyc, 2009). Contrapondo-se ao conhecimento dito tradicional, aquele produzido localmente por uma população a partir das suas práticas, o conhecimento dito científico é visto como aquele que reflete uma visão de mundo tipicamente 'moderna', 'racional', marginalizando-se assim o 'não racional', embebido no chamado 'tradicional' (Santos, 2008). Apesar de sua importância, essa discussão não é nosso objetivo neste momento. Nosso interesse é refletir sobre um instrumento de disponibilização dos resultados das pesquisas desenvolvidas em instituições acadêmicas.

O acesso a informações no processo de tomada de decisão política pode ser feito, hoje, por meio de diversas fontes, tais como os sites de busca e as bibliotecas digitais, que tornam o conhecimento imediatamente acessível pela divulgação de resumos ou de trabalhos completos; os workshops, que reúnem pesquisadores de reconhecido saber em uma dada área temática, técnicos e mesmo a sociedade civil; ou ainda por meio de consulta direta a especialistas (Carneiro, Rosa, Medeiros, 2008). Estas últimas formas de acesso vêm reafirmar a posição de Scott (2005), segundo a qual, no campo da política, as decisões seriam tomadas depois de um debate aberto, informado e baseado numa análise criteriosa de dados. Contudo, pesquisas anteriores (Carneiro, Laurent, Medeiros, 2008 ; Carneiro, Rosa, Medeiros, 2008) nos fazem acreditar que nem sempre esses fóruns de consulta 'aberta' incluem, verdadeiramente, a diversidade de conhecimentos sobre um dado tema ou questão.

Inserimos, assim, a presente pesquisa na perspectiva da difusão do conhecimento produzido pela ciência ${ }^{5}$ e do seu acesso pela política. De um lado, para que os tomadores de decisão formulem políticas de conservação ambiental, o acesso ao conhecimento científico se apresenta como uma das opções possíveis para fundamentação e justificativa. Quanto mais ampla for a possibilidade de acesso, maior será o leque de alternativas às decisões políticas. Por outro lado, o do conhecimento, fica a questão de sua acessibilidade. 
As informações, discutidas e avaliadas por um board de especialistas (a meta-análise), tornarse-iam mais facilmente instrumentalizadas para uso dos tomadores de decisão do que simplesmente colocar à disposição deles um sistema de acesso a uma grande variedade de artigos de qualidade e conteúdos distintos. Estamos a abordar, aqui, a comunicação entre os campos da ciência e da política a partir do uso de uma base digital como meio de difusão de conhecimentos que poderão ser acessados por todos, inclusive por aqueles que são responsáveis pela formulação de políticas públicas.

A necessidade do diálogo entre ciência e política vem sendo expressa por alguns grupos de pesquisa de diferentes áreas, como, por exemplo, aqueles que trabalham na interface entre as ciências naturais e sociais (Nobre, Lahsen, Ometto, 2008). Outros atentam para a escassez de estudos examinando, sistematicamente, a comunicação entre esses dois campos (Jones, Jones, Walsh, 2008). Segundo alguns autores, no caso da conservação do meio ambiente, esse diálogo é ainda mais urgente, tendo em vista a intensidade desse debate na sociedade (Pullin et al., 2004). Não é, porém, apenas na área da conservação da biodiversidade que esse diálogo tem muito a contribuir. É no contexto mais geral das mudanças ambientais globais e da busca da sustentabilidade das atividades humanas que a ponte entre os dois campos é imprescindível, como esclarecem Nobre, Lahsen e Ometto (2008). Além disso, para esses autores, o projeto da sustentabilidade vem questionar a tradicional separação ente a produção de conhecimento e a ação (p.526).

Identificamos como etapas fundamentais dessa ponte, primeiramente, a difusão dos resultados das pesquisas; em seguida, o acesso à produção acadêmica pelos formuladores de políticas públicas; finalmente, o mapeamento do conhecimento científico produzido e sua posterior análise, a fim de expor aos interessados o que está sendo produzido sobre os temas relativos às políticas ou aos problemas socioambientais. Na perspectiva da EBP, que pressupõe o uso da informação científica na formulação de políticas públicas, o acesso livre a repositórios digitais que armazenam conhecimentos científicos pode ser um elemento, portanto, facilitador desse diálogo entre os dois campos mencionados, permitindo aos tomadores de decisão política ampliar seu leque de escolhas. Segundo Kuramoto (2006), o acesso aos trabalhos disponíveis em repositórios digitais deve ser livre, mundial e perpétuo, com licença de uso, distribuição e exibição pública, como prega o movimento de acesso livre à informação científica.

Tendo como parâmetros os questionamentos expostos, efetuamos um mapeamento do conhecimento produzido nos programas de pós-graduação no Brasil, com base no Banco de Teses do Portal de Periódicos da Capes. A seleção desse banco como objeto de análise se justifica tanto por atender aos questionamentos sobre a difusão da produção acadêmica, como por possibilitar o acesso a esse conhecimento. O Banco é um importante repositório digital de teses e dissertações, uma ferramenta de divulgação e de consulta de uso público que dá visibilidade à produção acadêmica dos programas de pós-graduação brasileiros (PPGs).

No caso presente, priorizamos no levantamento os PPGs de três grandes áreas: Ciências Humanas, Ciências Econômicas e Multidisciplinar 6 . O trabalho abrangeu a produção da totalidade dos PPGs de conceito igual ou superior a 4 (de acordo com os critérios da Capes na época) e que focavam as duas temáticas de nosso interesse: agricultura e biodiversidade. 
Nesse sentido, nosso levantamento se diferencia de outros já realizados também no que se refere à questão ambiental nas ciências sociais, a exemplo do trabalho de Ferreira (2006), que analisa a internalização da questão ambiental nas ciências sociais no Brasil, tendo como objeto a trajetória do grupo de trabalho Ecologia, Políticas e Sociedade, da Anpocs o qual desempenhou um papel central na internalização das duas áreas acima, segundo a autora. Além disso, Ferreira apresenta a produção dos PPGs em sociologia, em ciências sociais e em programas interdisciplinares de oito universidades brasileiras e três instituições de pesquisa.

\section{Acessando conhecimento por meio de base digital Capes}

Abordamos aqui os resultados do levantamento da produção acadêmica, considerando as teses de doutorado defendidas nas universidades brasileiras sobre os temas da biodiversidade, da sustentabilidade e da agricultura familiar, nas áreas de conhecimento referidas. Apresentamos a justificativa da escolha da base digital da Capes, a metodologia empregada e os resultados estatísticos, de acordo com os critérios estabelecidos previamente no estudo.

\section{Por que selecionar o Banco de Teses de acesso livre da Capes?}

Para realizar o levantamento das teses, as bibliotecas digitais foram, desde o início, a opção escolhida, ainda que apresentem o inconveniente de dependerem do bom acesso à internet. A partir dessa opção, alguns ensaios foram feitos para selecionar o banco de dados a que iríamos recorrer. Inicialmente, optou-se pelas bibliotecas digitais cujas bases de dados fossem de acesso livre e capazes de reunir o maior número de teses defendidas nas diferentes instituições brasileiras de ensino superior.

Duas bases foram testadas: a da Capes e a do Instituto Brasileiro de Informação em Ciência e Tecnologia (Ibict). Cada uma delas tem suas próprias formatações de páginas de busca na internet, assim como de catalogação e apresentação das obras. Aquela que melhor se adequou ao nosso levantamento foi a base da Capes, pois seus recursos de busca permitem selecionar os dados por ano e por nível de titulação. Além disso, possibilitam, o cruzamento de mais de uma palavra-chave. Essas características da ferramenta de busca, que facilitaram o uso dos critérios previamente estabelecidos para a nossa pesquisa, foram fundamentais para a escolha, como veremos adiante.

O Banco de Teses é importante instrumento de acesso à produção de conhecimento, especificamente voltado para divulgar informações sobre teses e dissertações produzidas nas universidades brasileiras a partir de 1987. Segundo informação obtida na consulta feita em julho de 2008 a técnicos da Capes, responsáveis pela gestão do Banco, essa base digital ainda estava em processo de implementação e adaptação às necessidades dos usuários. ${ }^{7}$ Além disso, ela é anualmente atualizada com base nas novas informações enviadas pelos programas de pós-graduação do país. Isso imprimiu aos resultados aqui apresentados um caráter fotográfico, preliminar e temporal. Assim, os dados levantados para este estudo se referem àqueles registrados na base até novembro 2007.

Além de oferecer um retrato da produção sobre os temas de interesse da nossa pesquisa, esperamos possibilitar a reflexão sobre os problemas encontrados no acesso a essa produção 
acadêmica, imaginando que essa base de dados poderia ser uma das possíveis fontes de acesso a referências científicas para o uso dos formuladores de políticas pública.

\section{Procedimentos da pesquisa}

\section{Critérios de seleção das teses}

O objetivo específico deste levantamento foi identificar e classificar a produção dos programas de pós-graduação brasileiros, em nível de doutorado, e classificá-la conforme as categorias temáticas referidas adiante. Um primeiro critério utilizado para a seleção das teses foi a relação com o tema de interesse, que se expressa por meio de oito palavras-chave ${ }^{8}$ empregadas na busca das teses, a saber: agricultura; sustentabilidade; unidades de conservação; biodiversidade; natureza; ambiente; rural; e desenvolvimento rural. Numa primeira tentativa, verificou-se grande quantidade e diversidade de teses defendidas, quando acionada apenas a busca pela palavra-chave agricultura. Optou-se, então, por cruzá-la com os outros termos, totalizando sete diferentes combinações, que denominamos categorias temáticas: agricultura-biodiversidade; agricultura-rural; agricultura-unidades de conservação; agricultura-sustentabilidade; agricultura-natureza; agricultura-ambiente; agricultura-desenvolvimento rural. Outros dois critérios foram o grau da titulação e o ano de defesa. A partir das sete combinações foram levantadas as teses de doutorado registradas entre os anos 1997 e 2006.

O quarto critério foi o conceito dado pela Capes após o seu processo de avaliação trienal dos PPGs no Brasil. A avaliação trienal aqui considerada foi a de 2004, equivalente ao período 2001-2003, pois a de 2007 foi divulgada posteriormente ao nosso levantamento. Foram considerados apenas aqueles PPGs com conceito igual ou superior a 4, assumindose, assim, a avaliação da Capes como identificador de qualidade da produção selecionada. ${ }^{9}$

Das nove grandes áreas identificadas pela Capes, selecionamos Ciências Humanas, Multidisciplinar e Ciências Sociais Aplicadas, sendo que, nesta última, somente as teses em ciências econômicas e economia. Este foi o último critério de corte.

\section{Ferramenta de busca, seu uso e o acesso às teses}

A ferramenta de busca permite a localização a partir de diferentes entradas na página Pesquisa: autor, assunto e instituição (Figura 1). Para o nosso levantamento, a entrada foi feita pelos campos Assuntos - todas as palavras; e Nível e Ano Base. Assim, foram empregadas as palavras-chave conjugadas (já citadas), preenchendo-se o campo Assuntos; em seguida, cada ano da série temporal no campo Ano, e no campo Nível sempre o doutorado.

Ao preencher essa página, surge uma nova, com os resultados da busca e onde, na parte superior, aparece o número total de obras identificadas. A listagem apresentada é bastante geral e só estão identificados o nome do autor e título e ano da tese. Para maior detalhamento, é necessário acessar a página Resumo clicando-se sobre cada título, quando surgem, então, os dados do cadastro das teses, onde constam, entre outros, os campos com nome do autor, título da tese, o PPG e sua universidade, as palavras-chave do registro da tese, a banca examinadora e o resumo. A Base Capes não disponibiliza o texto integral da tese. 
O preenchimento do campo Assunto, na página Pesquisa, com as palavras-chave, faz com que a ferramenta de busca identifique as teses que tenham o(s) vocábulo(s) em diferentes campos de seus cadastros - no título, no resumo ou nas palavras-chave. No entanto, cabe registrar que o resultado dessa busca apresentou um erro de superdimensionamento, devido aos diversos significados que algumas palavras-chave podem assumir quando inseridas em outros contextos. Foi o caso, por exemplo, das palavras sustentabilidade, natureza e ambiente, como na seguinte frase: "reúnem dados e resultados empíricos que caracterizam o ambiente de atuação de tais políticas e oferecem subsídios...". Isso poderia 'mascarar' os resultados obtidos na primeira etapa da pesquisa, concentrada no levantamento quantitativo e não na análise de conteúdo das teses. ${ }^{10} \mathrm{~A}$ leitura do resumo foi o recurso empregado para selecionar as teses que tivessem relação apenas com nosso tema de interesse: a relação entre biodiversidade e agricultura.

Outro fator que dificultou o levantamento, decorrente da característica do motor de busca da Capes, foi o fato de que uma mesma tese podia ser selecionada mais de uma vez, em virtude da presença, nela, de mais de uma das palavras de busca. Esse dado nos mostrará, mais adiante, um resultado sobre a frequência de teses por categoria temática.

Figura 1: Página Pesquisa, do Banco de Teses da Capes

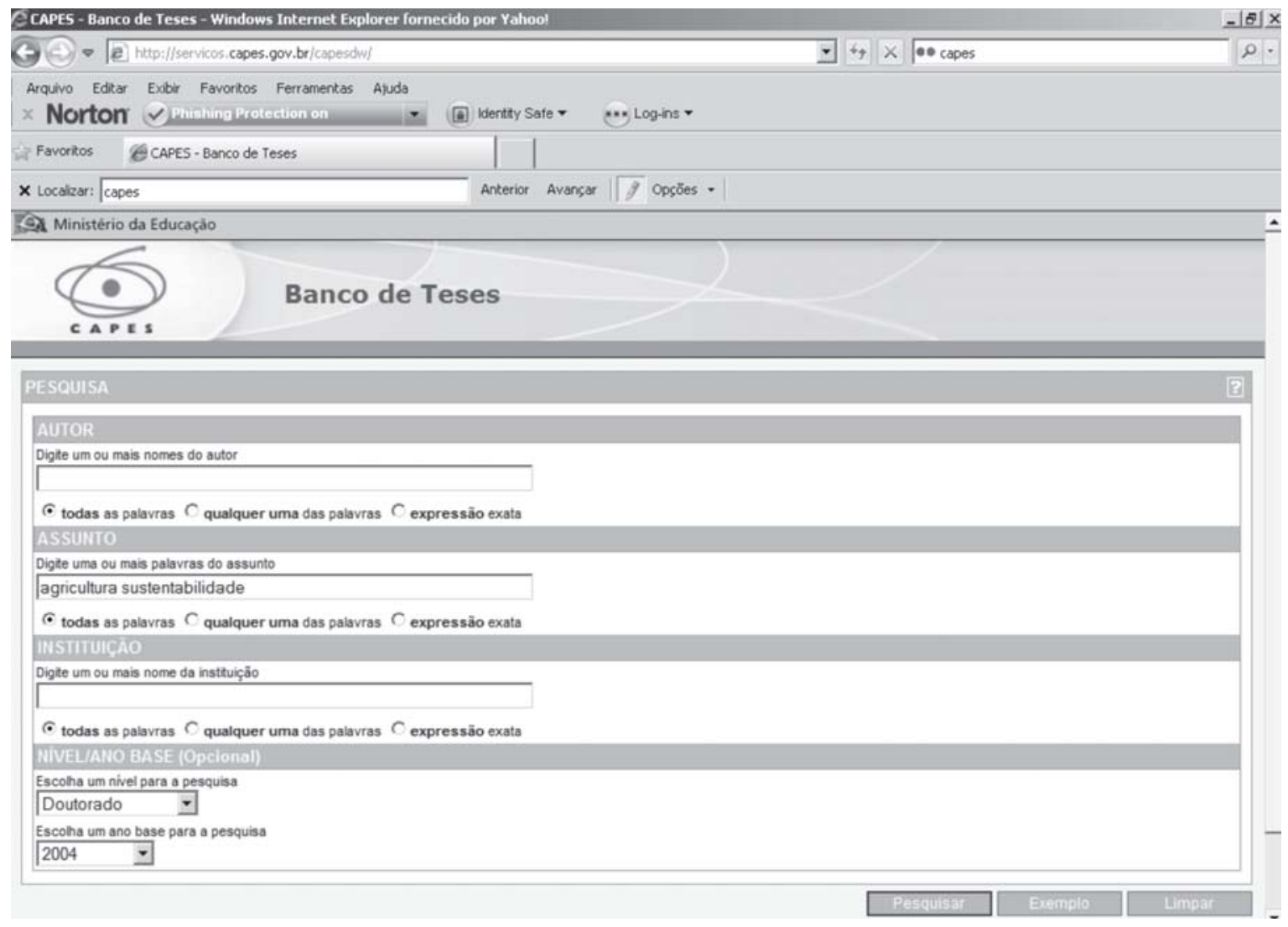

(http://www.capes.gov.br/servicos/banco-de-teses) 


\section{0 registro das teses: 0 banco de dados da pesquisa}

Com base nas informações contidas na página Resumo, criou-se um banco de dados da nossa pesquisa com o registro das teses selecionadas. Para tanto, foi construída uma planilha em que constavam os dados apresentados no Quadro 1. Como pode ser nele observado, além dos campos já disponíveis na página Resumo, foram inseridos outros (aqueles a partir do item 13) relativos à busca (como é o caso das palavras-chave da nossa pesquisa) e identificação do PPG (itens 24 a 27), bem como outros coletados no resumo das teses selecionadas (itens 28 a 34).

Quadro 1: Campos da planilha de registros das teses selecionadas

\begin{tabular}{|ll|}
\hline 1. autor & 19. agricultura e ambiente \\
2. título & 20. agricultura e natureza \\
3. ano & 21. agricultura e rural \\
4. universidade (sigla) & 22. agricultura e desenvolvimento rural \\
5. universidade (nome por extenso) & 23. nível (doutorado) \\
6. PPG constando no registro da tese & 24. conceito PPG Capes \\
7. orientador & 25. área Capes \\
8. palavras-chave no registro da tese & 26. grande área Capes \\
9. área de conhecimento/estudo no registro da tese & 27. estado onde se localiza a universidade \\
10. linha de pesquisa no registro & 28. região geográfica onde se localiza a universidade \\
11. resumo & 29. produto ao qual se refere \\
12. agência financiadora no registro & 30. temas/questões gerais \\
13. palavra-chave usada na busca em primeiro lugar & 31. estado (objeto de estudo) \\
14. número de vezes em que foi listada & 32. região (objeto de estudo) \\
15. uma vez listada & 33. bioma (objeto de estudo) \\
16. agricultura e biodiversidade & 34. unidade de conservação (objeto de estudo) \\
17. agricultura e unidade de conservação & 35. observações \\
18. agricultura e sustentabilidade & \\
\hline
\end{tabular}

\section{Resultados do levantamento}

Consideramos o universo geral da pesquisa o total das teses listadas após a primeira busca seguindo os critérios já elencados: categorias temáticas, anos de defesa e nível. Com isso, a listagem resultou bastante ampla, incluindo as diversas grandes áreas Capes. Essa inclusão se deve à estrutura da ferramenta de busca, que não tem um campo, em sua página Pesquisa, em que se possam incluir as grandes áreas de interesse do nosso estudo. Sendo assim, com os critérios da nossa pesquisa, foram relacionadas, inicialmente, 472 teses, divididas pelas nove grandes áreas Capes, como mostra o Gráfico 1.

É interessante notar que a grande área a apresentar o maior número de teses, segundo os nossos critérios, foi a de Ciências Agrárias (36,44\%), seguida pela de Ciências Humanas (23,52\%). Esta última, junto com as outras duas grandes áreas temáticas selecionadas, somaram, aproximadamente, 42,37\% do total desse universo geral, correspondendo a 192 teses. Foi sobre esse total que baseamos o nosso estudo. Esse montante representa, então, todas as teses registradas na base digital Capes até a data desta pesquisa (novembro 2007), que obtiveram conceito igual ou superior a 4, em PPGs das grandes áreas Ciências Humanas, Multidisciplinar e Ciências Econômicas, e que foram identificadas com base nas palavraschave escolhidas para a nossa pesquisa. 
Gráfico 1: Número total de teses por grande área (nov. 2007)

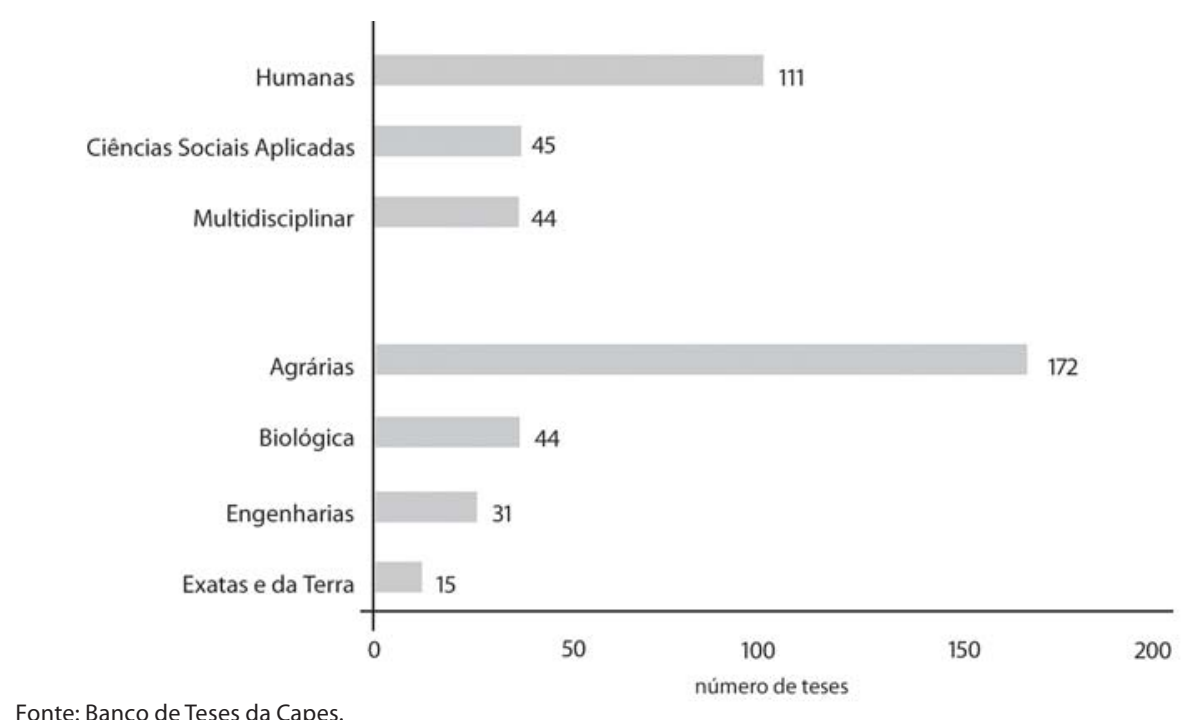

Fonte: Banco de Teses da Capes.

Essas 192 teses estão distribuídas por grande área e conceito Capes (Tabela 1), das quais:

- Quarenta por cento das teses foram defendidas em PPGs de conceito 5, seguido por $28,13 \%$ com conceito 4 ;

- Os dois conceitos máximos obtidos no processo de avaliação da Capes aparecem em destaque na área de Ciências Humanas, se comparados com as outras áreas: conceito 6 com $16,15 \%$ e conceito 7 com 10,42\%;

- Concentram-se na grande área Ciências Humanas 58\% das teses;

- Do total de teses defendidas, 64\% foram em PPGs de universidades localizadas na região Sudeste e, desse percentual, 70\% são em Ciências Humanas;

- Dos 19\% de teses defendidas em PPGs na região Sul, 61\% são da grande área Multidisciplinar.

Tabela 1: Distribuição das teses por grande área e conceito Capes

\begin{tabular}{cccc}
\hline CONCEITO CAPES & MULTIDISC. & ECONOMIA & HUMANAS \\
\hline $\mathbf{4}$ & 16 & 9 & 29 \\
$\mathbf{5}$ & 28 & 18 & 31 \\
$\mathbf{6}$ & 0 & 10 & 31 \\
$\mathbf{7}$ & 0 & 0 & 20 \\
\hline Total & $\mathbf{4 4}$ & $\mathbf{3 7}$ & $\mathbf{1 1 1}$ \\
\hline
\end{tabular}

Fonte: Banco de Teses da Capes.

\section{Resultados da pesquisa por grandes áreas da Capes e por categoria temática}

Apresentamos nesta seção a distribuição das 192 teses identificadas, por grande área da Capes e por categoria temática.

A grande área Multidisciplinar apresentou 44 teses, distribuídas por 12 PPGs (Gráfico 2). O PPG com mais teses identificadas foi o de Meio Ambiente e Desenvolvimento, da 
Universidade Federal do Paraná (conceito Capes 4), seguido pelo de Desenvolvimento Sustentável, da Universidade de Brasília (conceito 5). Ambos concentram 50\% das teses da grande área. Se somarmos a produção do PPG de Ciências Ambientais da Universidade Federal de Goiás, chegamos a 61,36\% (número absoluto) das teses encontradas nessa grande área.

O total da grande área Ciências Econômicas é de 37 teses. Estão distribuídas em 11 diferentes PPGs (Gráfico 3), subdivididos pelas seguintes subáreas: Ciências Econômicas, Ciências (economia aplicada), Desenvolvimento Econômico, Economia Rural, Economia Aplicada e Economia. Esta última concentra cinco instituições de ensino superior. O PPG em Ciências da Escola Superior de Agricultura Luiz de Queiroz/USP (conceito Capes 6) tem o maior número de teses identificadas a partir das categorias da pesquisa.

Gráfico 2: Teses por PPGs - grande área Multidisciplinar

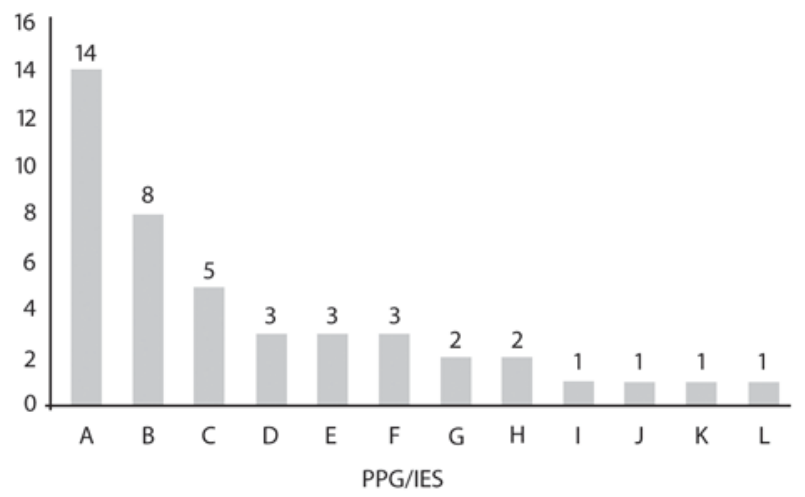

Legenda: A - Meio ambiente e desenvolvimento (UFPR); B - Desenvolvimento sustentável (UnB); C - Ciências ambientais (UFGO); $D$ - Ciências humanas (UFSC); E - Desenvolvimento sustentável do trópico úmido (UFPA); F - Interdisciplinar em ciências humanas (UFSC); G - Ciências humanas (interdisciplinar) (UFSC); H - Recursos naturais (UFCG); I - Agronegócios (UFRS); J - Planejamento de sistemas energéticos (Unicamp); K - Planejamento energético (UFRJ); L - Política científica e tecnológica (Unicamp).

Fonte: Banco de Teses da Capes.

Gráfico 3: Teses por PPG - grande área Ciências Econômicas

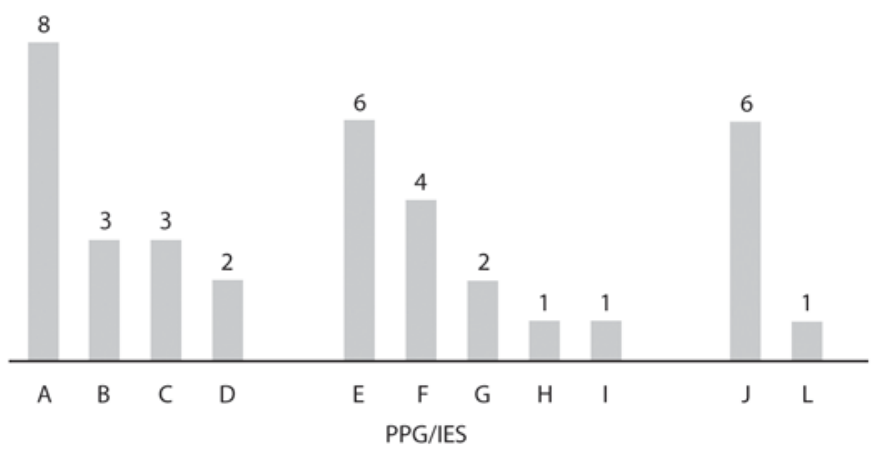

Legenda: A - USP/ESAL; B - Unicamp; C - UFViçosa; D - Unicamp; E - Unicamp; F - UFPE; G - USP; H - UFRS; I - PUC-RJ; J - UFViçosa; $\mathrm{L}$ - Unicamp.

Fonte: Banco de Teses da Capes. 
A grande área Ciências Humanas totaliza 111 teses, distribuídas por 14 PPGs, de conceitos 4 a 7, de 39 instituições de ensino superior. E 80\% das teses se concentram em duas das cinco áreas do conhecimento que fazem parte dessa grande área: Sociologia e Geografia (Gráfico 4).

Apresentamos a seguir a frequência das teses por palavras-chave e por grandes áreas da Capes. Relembramos que, para identificar o universo estudado na base da Capes, foram empregadas as sete palavras-chave conjugadas com a palavra agricultura. É essa combinação que denominamos categorias temáticas.

$\mathrm{Na}$ área Ciências Econômicas, duas categorias temáticas não foram contempladas: agricultura-biodiversidade e agricultura-unidades de conservação (Gráfico 5). Apenas cinco teses apareceram na categoria agricultura-sustentabilidade. A que apresentou a maior frequência de teses foi, como era de se esperar, agricultura-rural. Isso significa que das 36 teses de ciências econômicas, 22 ( $76 \%$ do total) foram identificadas na base da Capes por terem citado a categoria temática agricultura-rural. Já agricultura-ambiente reúne 38\% das teses dessa área de conhecimento.

Gráfico 4: Teses por PPGs - grande área Humanas

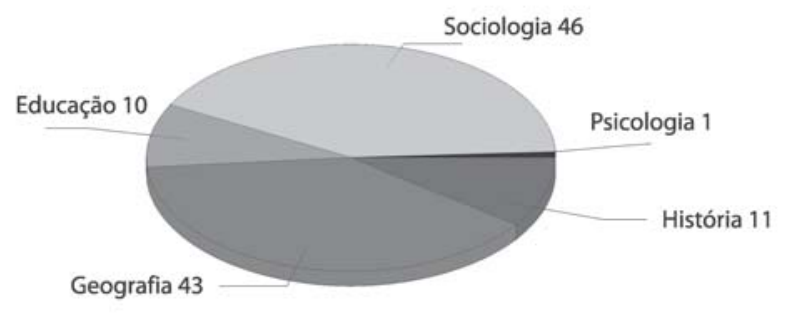

Fonte: Banco de Teses da Capes.

Gráfico 5: Teses por PPGs em grande área Humanas - área Sociologia

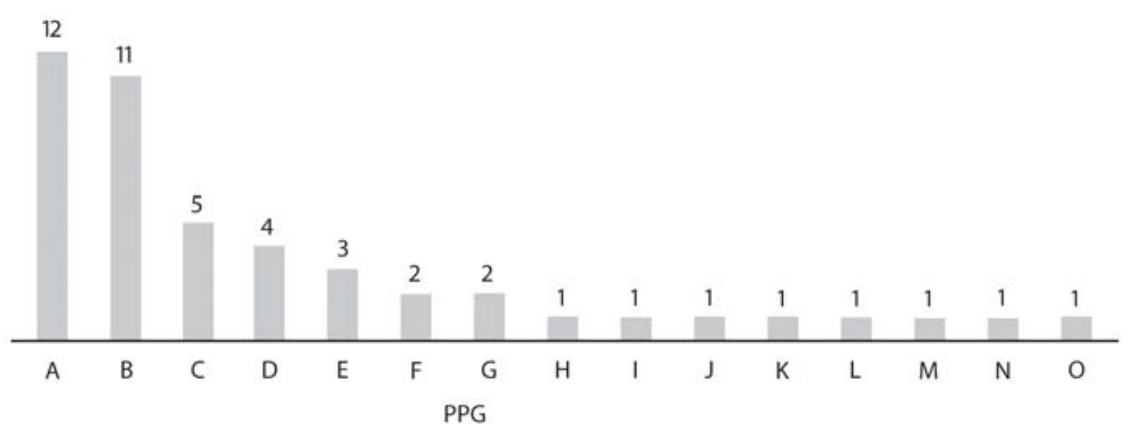

Legenda: A - Desenvolvimento, Agricultura e Sociedade (UFRRJ); B - Ciências sociais (Unicamp); C - Sociologia (UFRGS); D - Ciências Sociais (PUC-SP); E- Sociologia (UnB); F- Sociologia (UFPB); G - Ciências Sociais (UFRN); H - Sociologia (UFPE); I- Sociologia (PUC-SP); J - Sociologia (UFPB/J. Pessoa); L - Sociologia(UNESP/Araraquara); M - Sociologia (UFC); N - Sociologia (USP); O - Ciência socialAntropologia Social (USP).

Fonte: Banco de Teses da Capes.

Na grande área Multidisciplinar, a maior frequência foi da categoria agriculturaambiente, com $64 \%$ das teses selecionadas, seguida de agricultura-natureza, com $44 \%$ do universo de 44 teses (Gráfico 6). A categoria agricultura-sustentabilidade selecionou 33\% 
do universo das teses dessa grande área, enquanto agricultura-unidades de conservação, $8 \%$, e agricultura-biodiversidade, $15 \%$.

Na grande área Ciências Humanas, a categoria de maior frequência foi agriculturarural, somando 71 teses (64\%) do total de 111 dessa grande área (Gráfico 7). Em seguida, aparece a categoria agricultura-desenvolvimento rural (43\%). As categorias temáticas com menor frequência são: agricultura-unidades de conservação $(0,9 \%)$, agricultura-biodiversidade (5\%) e agricultura-sustentabilidade (14\%).

\section{Gráfico 6: Teses por palavras-chave - grande área Ciências Econômicas}

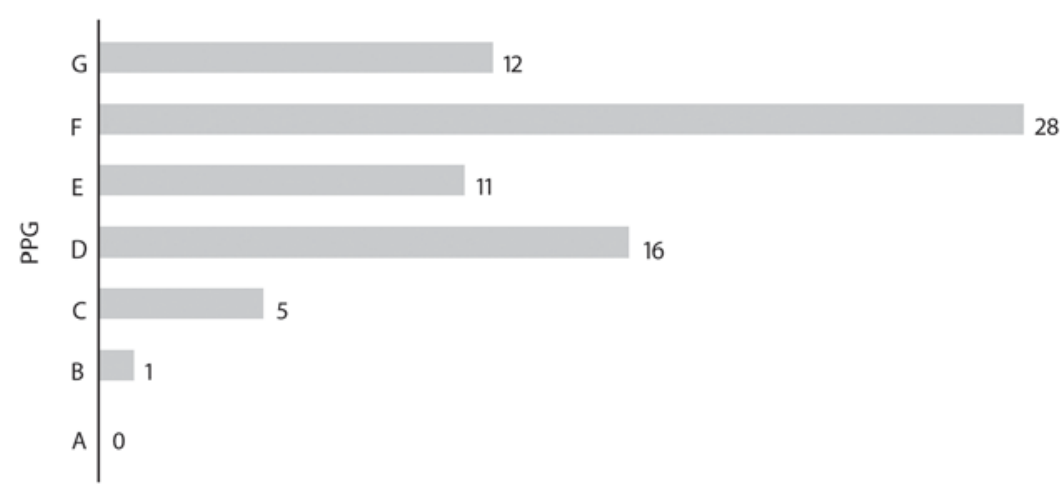

Legenda: A - Agricultura e biodiversidade; B - Agricultura e unidade de conservação; C - Agricultura e sustentabilidade; $\mathrm{D}$ - Agricultura e ambiente; $\mathrm{E}$ - Agricultura e natureza; F - Agricultura e rural; G -Agricultura e desenvolvimento rural. Fonte: Banco de Teses da Capes.

Gráfico 7: Teses por palavras-chave - grande área Multidisciplinar

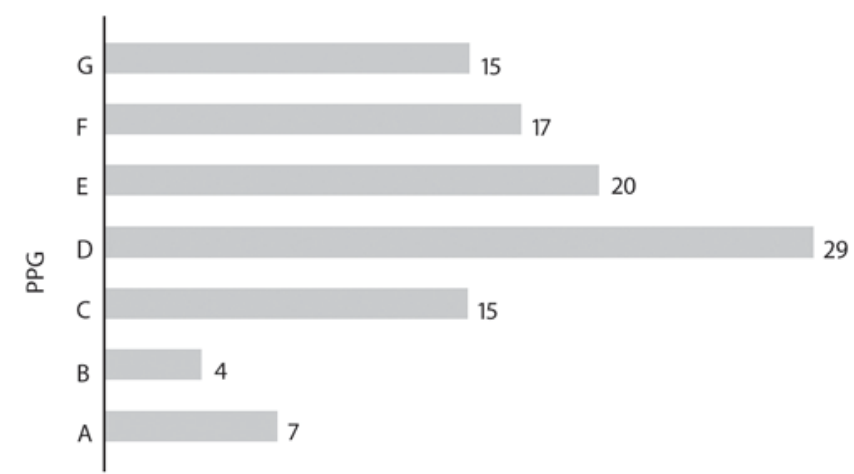

Legenda: A - Agricultura e biodiversidade; B - Agricultura e unidade de conservação; C - Agricultura e sustentabilidade; D Agricultura e ambiente; $\mathrm{E}$ - Agricultura e natureza; F- Agricultura e rural; $\mathrm{G}$-Agricultura e desenvolvimento rural.

Fonte: Banco de Teses da Capes.

\section{Ruídos da comunicação}

Acreditava-se que esse quadro de resultados pudesse ser um espelho, mesmo que preliminar, da realidade da produção acadêmica em nível de doutorado, em programas de pós-graduação no país na interface dos campos social e ambiental. No entanto, constatouse certa miopia, pelo menos com relação à meta desse levantamento. Primeiro, foi detectada a ausência de PPGs das grandes áreas escolhidas que pudessem ter teses relativas à nossa 
questão central. É o caso de programas de antropologia, entre outros, bem como aqueles que têm produção na interface dos dois campos de conhecimento mencionados. Segundo, a ferramenta de busca não identificou teses de doutorado que eram de nosso conhecimento, como as do Programa de Ciências Sociais em Desenvolvimento, Agricultura e Sociedade, da UFRRJ. Inicialmente, duas hipóteses foram apontadas para esses problemas: o processo de cadastramento das teses e a metodologia empregada pela pesquisa.

\section{O cadastramento das teses}

Conferindo as teses cadastradas no Banco Capes com as listadas em algumas bibliotecas virtuais de PPGs, verificamos que nem todas as teses defendidas nesses programas estavam cadastradas. Fica evidente que o Banco de Teses não espelhou a realidade absoluta da produção acadêmica brasileira - pelo menos até a data do presente levantamento. Isso já é um fator limitante. Afinal, pelo exposto, pode existir um número considerável de teses que, não estando ainda cadastradas, não são listadas pela ferramenta de busca nem identificadas por qualquer tipo de pesquisa bibliográfica que use o Banco.

O cadastramento das teses se refere àquelas defendidas a partir de 1987. Segundo informação obtida junto ao setor Portal Periódico daquela instituição, o cadastro com o texto completo das teses tornou-se obrigatório apenas a partir de 2006. Ele é feito, anualmente, pelas instituições de ensino superior, por meio de seus PPGs, sendo estes os responsáveis pelo conteúdo disponibilizado na base da Capes. ${ }^{11}$ Em outras palavras, o cadastramento é feito de acordo com as condições locais e administrativas de cada PPG. Isso ocorre sem qualquer intervenção dos técnicos da Capes, os quais apenas fazem uma verificação quanto à veracidade dos dados quando estes são alterados pelos autores das teses cadastradas. ${ }^{12}$ As dificuldades operacionais de cada Programa e sua adaptação a esse registro podem ser fatores responsáveis por lacunas observadas no cadastramento.

\section{A ferramenta de busca e o uso de palavras-chave da pesquisa}

Considerando que algumas teses não apareciam no nosso levantamento, procedemos a uma verificação a partir dos registros online dos próprios PPGs. Escolheu-se aleatoriamente um ano para análise e três PPGs conhecidos das autoras. Isso foi feito usando-se o recurso 'localizar nesta página', do Windows Internet Explorer, e as palavras-chave para a identificação das teses. Depois, voltando ao Banco de Teses Capes, confirmou-se que as teses identificadas por esse procedimento não estavam listadas por ocasião do levantamento feito inicialmente ${ }^{13}$ no estudo.

Por que, então, não suprimir esse cruzamento? O recurso do cruzamento foi utilizado, principalmente, como estratégia de identificação, com maior precisão, das teses que abarcassem a temática central da pesquisa. Do contrário, todo e qualquer trabalho que versasse sobre uma única palavra-chave seria listado pela busca. A título de exemplo: usando a palavra-chave sustentabilidade, foram listadas 73 teses de doutorado, em 2004, nas áreas de conhecimento as mais diversas: Planejamento Integrado dos Recursos Hídricos, Controle Ambiental, Geoecologia, Avaliação, Zootecnia (produção e conservação de forragens), Botânica, Ciências Biológicas, Ecologia, Sensoriamento Remoto, Planejamento Energético 
(balanços globais de matéria e energia), Engenharia Agrícola (engenharia de água e solo), Ciências da Engenharia Ambiental, Engenharia de Produção. Tamanha diversidade, além de fugir das áreas de interesse da nossa pesquisa bibliográfica e da questão-chave que a orienta, acabaria por redirecionar o foco sobre a questão da comunicação entre os campos da ciência e da política.

Essa amplitude de áreas de conhecimento acionadas por uma única palavra-chave exigiria, por parte de um formulador de políticas imaginário, usuário do Banco da Capes, uma habilidade para a qual, talvez, não esteja ainda capacitado, ou mesmo simplesmente habituado (Scarano, Oliveira, 2005). O exemplo mostra que ele teria um trabalho de leitura razoável, o que exigiria grande disponibilidade de tempo, visto o número crescente de teses defendidas nos últimos anos; além de demandar a sua capacidade de avaliar os resumos das teses levantadas para os seus objetivos específicos. Imaginando-o durante o processo de elaboração de uma política, ele recorreria ao conhecimento acadêmico na busca de informações (dados, evidências...), capazes de informá-lo sobre uma temática bastante específica.

Sabe-se que o tempo urge, na maioria das vezes, nesse processo de formulação de política pública (Carneiro, Laurent, Medeiros, 2008; Carneiro, Rosa, Medeiros, 2008), e uma pesquisa bibliográfica que disponibilize essa diversidade e exija esse tipo de trabalho, ao invés de facilitar, dificulta o acesso ao conhecimento produzido sobre uma dada temática ou região geográfica. Em outras palavras, no lugar de facilitar a comunicação entre a ciência e a política (o que seria desejável), esse tipo de resultado de busca aumenta o ruído habitualmente existente entre os dois campos (Brasil, 2008), o que pode comprometer a prática e a efetividade da política pública em alcançar sua meta principal.

Segundo informação obtida junto ao setor Portal de Periódicos da Capes, a seleção feita pela ferramenta de busca identifica o assunto (no caso da nossa pesquisa, as palavraschave) em qualquer um dos campos constantes da ficha de registro da mesma. ${ }^{14}$ No entanto, constatamos que essa informação não procede, pois algumas teses não são listadas pela ferramenta de busca quando se empregam palavras do campo Linha de Pesquisa, por exemplo. Além disso, foi também afirmado pelos técnicos da Capes ${ }^{15}$ que o aplicativo usado para o Banco de Teses é de uso limitado, pois não dá opções para se realizar pesquisa com várias palavras-chave, o que pode explicar o problema encontrado quando do uso da ferramenta de busca para o levantamento. Foi-nos esclarecido, também pela mesma fonte, que o Banco de Teses não foi criado para ser uma ferramenta de pesquisa bibliográfica, que exigiria o uso de diferentes filtros, como no presente caso. Seu objetivo inicial era, simplesmente, ser um 'repositório' de informações. Mas, mesmo limitado a tal condição, ele tem a função de difundir a informação, estando aberto ao uso por diversos usuários.

Finalmente, o teste realizado com a ferramenta de busca em questão apresentou muitas limitações e dificuldades para o objetivo a que nos propomos, qual seja, o de servir de instrumento de acesso ao conhecimento por técnicos envolvidos na elaboração de políticas públicas. Tais dificuldades seriam ainda maiores no caso de temas multidisciplinares, como em geral o são os relacionados à questão ambiental, pois exigiriam acessar saberes originários de diferentes áreas de conhecimento. O teste evidenciou que a comunicação entre ciência e política, no caso brasileiro, parece ser caracterizada por muitos ruídos e poucos feedbacks, traduzindo-se, assim, numa comunicação confusa. 


\section{Diálogo possível ou comunicação difícil?}

A questão da comunicação entre os dos dois campos, o da ciência e o da política, é de grande relevância, principalmente se considerarmos a possibilidade de o recurso aos conhecimentos científicos na elaboração de políticas públicas resultar em práticas mais efetivas. Tendo em vista a produção científica brasileira na área da conservação de recursos naturais, a pouca efetividade das políticas públicas ambientalistas no alcance de suas metas parece apontar uma dificuldade na comunicação entre esses dois campos (Scarano, 2007). ${ }^{16}$ Como o escopo geral em que se insere o presente levantamento é o da elaboração de políticas baseadas em evidência, a comunicação entre os campos político e científico vem à tona como elemento primordial - o que é, justamente, revelado por nosso estudo.

No relatório acerca do processo de consulta nacional sobre a comunicação entre ciência e políticas públicas no campo da biodiversidade (Brasil, 2008), a dificuldade de diálogo ${ }^{17}$ entre pesquisadores e tomadores de decisão foi tema recorrente. Ela é citada como obstáculo em nível local e internacional (Young, 2005); como mecanismo a ser aperfeiçoado; e como item capaz de mobilizar atores sociais variados e cientistas em torno da conservação da biodiversidade. Portanto, uma base de dados que, por natureza, centralizasse informações sobre a produção acadêmica e científica no país, como é o Banco de Tese da Capes, poderia ser considerada um dos elementos estruturais desse diálogo, pois facilitaria e viabilizaria a comunicação entre esses campos e, o que é mais significativo, contribuiria para aumentar o leque de alternativas para que formuladores de políticas públicas alcançassem seus objetivos.

Apesar de a pesquisa bibliográfica aqui narrada mostrar as grandes possibilidades do uso desse meio na divulgação de estudos científicos, as dificuldades descritas indicam limites e problemas quanto ao uso dessa base de dados para tal fim. Compreendemos que, ao menos no caso das temáticas ambientais, os limites e problemas encontrados podem comprometer a comunicação entre pesquisadores e formuladores de política, quando estes últimos buscam subsídios para melhor fundamentar a formulação de medidas públicas. O fato é ainda mais surpreendente quando se leva em conta que o mundo da internet, no qual as bases digitais se localizam, visa a aumentar e qualificar a comunicação entre grupos e pessoas; afinal trata-se de uma ferramenta de busca digital, de acesso livre ou aberto à informação científica. O conceito de acesso livre subentende uma difusão imediata, ampla e irrestrita de informações, de modo a torná-las mais visível (Kuramoto, 2006; Swan, 2008; Gauz, 2008). No caso aqui, trata-se da divulgação da produção acadêmica.

A dificuldade a que nos referimos, do uso do Banco de Teses da Capes, pode ser vista também como exemplo dos problemas apontados na literatura sobre a comunicação científica de acesso livre, em especial no Brasil: barreira à visibilidade dos resultados de pesquisas e, consequentemente, baixo impacto da produção científica (Swan, 2008). Isso sem mencionar a contribuição, incerta, da ciência para o campo da política. Nesse sentido, a instituição em questão, tendo em vista sua missão, está, no mínimo, perdendo a oportunidade que fornece a tecnologia dos nossos dias de poder cooperar nessa comunicação. 


\section{Considerações finais}

A pesquisa bibliográfica cujos resultados ora apresentamos se situa num debate mais abrangente e atual, que envolve o recurso aos conhecimentos científicos pelos formuladores de políticas públicas por meio de bancos de dados de acesso livre. Ela pretende colaborar para a compreensão das relações entre ciência e política a partir do recorte metodológico que privilegia dois temas: a agricultura e a biodiversidade. Além disso, os resultados vêm, também, acrescentar mais elementos sobre a institucionalização, no Brasil, do campo usualmente conhecido como ambiente e sociedade, e sobre a evolução da produção científica brasileira a ele associada.

O banco de teses construído preliminarmente pela nossa pesquisa não espelha a totalidade da produção acadêmica brasileira sobre o tema selecionado. A base de dados da Capes apresentou alguns limites para o objetivo que desejávamos alcançar - mapear o estado da arte sobre determinada temática.

A partir do levantamento realizado, discutimos os problemas no acesso a um repositório digital de dados científicos, o Banco de Teses da Capes, mais especificamente a partir da difusão dos resultados de pesquisas na área das ciências humanas envolvendo a agricultura e a sua contribuição para a conservação da diversidade biológica, e as dificuldades na comunicação entre ciência e política daí decorrentes. Isso porque o diálogo entre ciência e política poderia cooperar para a maior efetividade desta última, primordialmente se as políticas públicas puderem integrar, na fase da sua elaboração, conhecimentos produzidos cientificamente. A partir do exemplo do Banco de Teses da Capes, seu uso nos aponta para alguns limites e problemas quanto ao uso de bases digitais de acesso livre visando à difusão de pesquisas e seus resultados. Os ruídos encontrados podem comprometer o diálogo entre os dois campos, tão necessário num contexto nacional e internacional em que as políticas encontram dificuldades em alcançar seus objetivos.

A abordagem da formulação de políticas informadas por evidências ou conhecimentos científicos aponta, como pudemos ver, algumas questões muito importantes. Essa abordagem traz o conhecimento científico (e, por consequência, a ciência e o cientista) para o campo da política, evidenciando a responsabilidade, por um lado, dos pesquisadores na produção e difusão de resultados e, por outro, dos tomadores de decisão nos impactos das políticas sobre a sociedade e a natureza. E isso, principalmente, se focamos o caso que nos interessa: a agricultura e a conservação da biodiversidade. Ademais, ela dá margem a pensar o papel que os formuladores têm, por meio das suas decisões, concepções e representações, na conservação da biodiversidade e no desenvolvimento e implantação da política. Por fim, essa perspectiva traz para o centro do debate a questão da comunicação entre ciência e política, que remete às linguagens e racionalidades específicas de cada um dos dois campos, bem como à questão do acesso aos saberes e resultados das pesquisas científicas e dos seus usos no campo das políticas públicas.

Finalmente, acreditamos e reconhecemos que, apesar das limitações, o Banco de Teses da Capes tem seu papel como instrumento de acesso livre na divulgação de resultados de pesquisas acadêmicas, contribuindo para sua maior visibilidade. Ele pode contribuir para estabelecer um panorama (mesmo que fotográfico) da produção acadêmico-científica por 
PPG. Um aperfeiçoamento da própria estrutura de funcionamento do Banco sob novas metas e prioridades seria possível ao se partir dos problemas detectados por seus usuários. Mais do que tudo, é crucial e urgente a sua reestruturação, visto que a missão da Capes é divulgar a produção acadêmica brasileira e tornar mais ágil o acesso às informações básicas de teses e dissertações defendidas em programas de pós-graduação no país.

\section{NOTAS}

${ }^{1}$ A meta-análise dos conteúdos das teses mapeadas será objeto de uma etapa posterior de pesquisa, na qual as informações coletadas serão sistematizadas por meio de critérios previamente estabelecidos.

${ }^{2}$ Ele é financiado pela Agence Nationale de Recherches (ANR), França, e pelo Conselho Nacional de Desenvolvimento Científico e Tecnológico (CNPq), Brasil.

${ }^{3}$ Essa tentativa de melhoria pode ocorrer no caso das políticas ambientais, principalmente no caso de políticas de conservação da biodiversidade, das quais ainda se tem resultados insatisfatórios, evidenciados pela degradação ambiental, pela dificuldade de implantação de unidades de conservação, pelos longos processos de licenciamento ambiental de obras e pelos processos de negociação de metas de redução de emissões.

4 "All types of science and social science knowledge generated by a process of research and analysis either within or without the policy-making institution"; tradução livre.

${ }^{5}$ A difusão do conhecimento é parte do sistema de comunicação científica, considerado a infraestrutura da comunidade científica (Mueller, 2006). A comunicação se utiliza de diferentes canais, tanto em meio impresso como em meio eletrônico, com acesso aberto ou não. Apesar do debate sobre a questão da legitimação desses últimos canais, eles vêm sendo cada vez mais reconhecidos pela comunidade científica e pelos órgãos de fomento no país.

${ }^{6}$ Até 2008, a área Multidisciplinar foi parte da grande área chamada Outras. Em 2009, essa grande área passou a ser chamada Multidisciplinar, sendo então dividida em quatro novas áreas, entre elas a Interdisciplinar.

${ }^{7}$ Em dezembro de 2008, a consulta ao Banco de Teses mostrou que algumas alterações foram feitas, como por exemplo o acesso ao cadastro de teses, que antes podia ser alterado mais facilmente pelo próprio autor.

${ }^{8}$ Empregamos as mesmas palavras-chave utilizadas em outra pesquisa de nossa equipe, sobre a produção científica relativa a agricultura e biodiversidade em revistas científicas brasileiras, na área de economia e ciências sociais. Além de estarem relacionadas à temática de interesse, procurou-se empregar palavras que são termos usualmente utilizados na indexação e recuperação de documentos, abrangendo assim áreas de conhecimento próprias às atividades de pesquisa.

${ }^{9}$ Os conceitos atribuídos pela Capes correspondem a: 4 - bom desempenho; 5 - alto nível de desempenho, sendo este o maior conceito admitido para programas que ofereçam apenas mestrado; 6 e 7 - exclusivos para programas que ofereçam doutorado com nível de excelência, desempenho equivalente ao dos mais importantes centros internacionais de ensino e pesquisa (ver http://www.capes.gov.br/avaliacao/resultadosda-avaliacao-de-programas/2315).

${ }^{10}$ Esta análise será objeto de outra etapa da pesquisa, a ser ainda desenvolvida.

${ }^{11}$ No site da instituição, isso está claro: “As informações constantes desta base de dados são fornecidas diretamente à CAPES pelos programas de pós-graduação mantidos por universidades e instituições de pesquisa brasileiras e são de sua inteira responsabilidade. O uso da base de dados e de seus registros está sujeito a todas as leis de direitos autorais aplicáveis"(http://www.capes.gov.br/servicos/bancoteses.html; acesso em out. 2007).

${ }^{12}$ Até o momento desta consulta junto ao setor da Capes, os autores tinham a possibilidade de entrar nos cadastros de suas teses e alterá-los usando apenas os seus CPFs, o que foi testado e confirmado por nós.

${ }^{13}$ Com o uso das categorias temáticas do estudo, isto é, o cruzamento das palavras-chave com a palavrachave agricultura a fim de melhor focar a identificação das teses para o levantamento.

${ }^{14}$ Estes campos são os mesmos que apareceram na página Resumo da Base. 
${ }^{15}$ Em junho de 2008 foi feita uma visita ao setor responsável pelo banco de teses, a Coordenação Geral do Portal de Periódicos, para se compreender os limites por nós detectados no uso da ferramenta de busca do Banco Capes.

${ }^{16}$ Dificuldade que não é restrita à área ambiental, ocorrendo também na área de desenvolvimento (Young, 2005).

${ }^{17}$ Pelos menos três grandes diferenças entre pesquisadores e tomadores de decisão são apontadas: as prioridades, a escala de tempo no desenvolvimento de ações por cada ator e a diferença das linguagens empregadas.

\section{REFERÊNCIAS}

BRASIL.

Ministério de Meio Ambiente. National consultation meeting for creating a scientific advisory mechanism regarding policy decisions on the scope of the Convention on Biological Diversity and the Brazilian Govenment: final report. Brasília: Ministério do Meio Ambiente. 2008.

CARNEIRO, Maria José; LAURENT, Catherine; MEDEIROS, Camila.

O (im)possível diálogo entre ciências (sociais) e política pública na proteção da biodiversidade. Trabalho apresentado na 26. Reunião Brasileira de Antropologia, Porto Seguro. 2008.

CARNEIRO, Maria José; ROSA, Teresa da Silva; MEDEIROS, Camila.

Scientific evidences in the environmental Brazilian governmental police. Paper presented at First International Sociological Association Forum of Sociology, Sessions 16-17:

Democratizing Knowledge and Democratizing Power, Barcelona. 2008.

DA-SILVA-ROSA, Teresa.

L'Union Européene et le co-financement des ONGs: discours idéologique ou conscience ecológique? Thèse (doctorat) - École des Hautes Études en Sciences Sociales, Paris. 2005.

DAVIES, Huw T.O.; NUTLEY, Sandra M. Evidence-based policy and practice: moving from rhetoric to reality. Paper presented at Third International, Inter-disciplinary Evidence-Based Policies and Indicator Systems Conference, Durham. 2001.

FERREIRA, Leila da Costa.

Idéias para uma sociologia da questão ambiental no Brasil. São Paulo: Annablume. 2006.

GALVÃO, Cristina M.; SAWADA, Namie O.; ROSSI, Lídia A.

A prática baseada em evidências: considerações teóricas para sua implementação na enfermagem perioperatória. Revista LatinoAmericana de Enfermagem, Ribeirão Preto, v.10, n.5. Disponível em http://www.scielo.br/pdf/ rlae/v10n5/v10n5a10.pdf. Acesso em: 10 dez 2008. 2002.

GAUZ, Valeria.

A alma da Internet e o acesso livre à informação científica. Liinc em Revista, Brasília, v.4, n.2, p.274-285. Disponível em: http:// revista.ibict.br/liinc/index.php/liinc/article/ view/246/178. Acesso em: 12 dez. 2008. 2008.

GEORGESCU-ROEGEN, Nicholas.

La décroissance: entropie, écologie, économie. Paris: Sang de la Terre. 1995.

HASTRUP, Kirsten.

Getting it right: knowledge and evidence in anthropology. Anthropological Theory, v.4, n.4, p.455-472. 2004.

JONES, Nicola; JONES, Harry; WALSH, Cora. Political science?: strengthening science-policy dialogue in developing countries. London: Overseas Development Institute. (Working Paper, 294). 2008.

JUNTTI, Meri; RUSSEL, Duncan;

TURNPENNYC, John.

Evidence, politics and power in public policy for the environment. Environmental Science and Policy, Exeter, v.12, n.3, p.207-215. 2009.

KURAMOTO, Hélio.

Informação científica: proposta de um novo modelo para o Brasil. Ciência da Informação, Brasília, v.35, n.2, p.91-102. 2006.

MUELLER, Suzana P. Machado. A comunicação científica e o movimento de acesso livre ao conhecimento. Ciência da Informação, Brasília, v.35, n.2, p.27-38. 2006.

NOBRE, Carlos; LAHSEN, Myanna; OMETTO, Jean.

Global environment change research: empowering developing countries. Annals of the Brazilian Academy of Science, Rio de Janeiro, v.83, n.3, p.523-529. 2008. 
NUTLEY, Sandra; WALTER, Isabel; DAVIES, Huw T.O.

Using evidence: how research can improve public services. Bristol: The Policy Press. 2007.

PULLIN, Andrew S. et al.

Do conservation managers use scientific evidence to support their decision-making? Biological Conservation, Essex, v.119, n.2, p.245-252. 2004.

SANTOS, Boaventura de S.

Um discurso sobre as ciências. São Paulo: Cortez. 2008.

SCARANO, Fábio.

Perspectives on biodiversity science in Brazil. Scientia Agrícola, Piracicaba, v.64, n.4, p.439-447. 2007.

SCARANO, Fábio; OLIVEIRA, Paulo.

Sobre a importância da criação de mestrados profissionais na área de ecologia e meio ambiente. Revista Brasileira de Pós-gradução, Brasília, v.2, n.4, p.90-96. 2005.

SCOTT, Christopher.

Measuring up to the measurement problem: the role of statistics in evidence based policymaking. London: London School of Economics. 2005

SWAN, Alma.

Why open access for Brazil? Liinc em Revista Brasília, v.4, n.2, p.158-171. Disponível em: http://revista.ibict.br/liinc/index.php/liinc/ article/view/279 . Acesso em: 12 dez. 2008. 2008.

YOUNG, John.

Research, policy and practice: why developing countries are different. Journal of International Development, v.17, n.6, p.727-735. 2005.

\section{$\rightarrow \rightarrow \rightarrow<<<$}

